\title{
Diez tesis \\ sobre la crisis de la modernidad ${ }^{1,2}$
}

\author{
Víctor M. Toledo
}

Centro de Investigaciones en Ecosistemas, UNAM campus Morelia, México.

Email: vtoledo@oikos.unam.mx

Resumen: Se hace una apretada síntesis de lo que significa la crisis de la civilización industrial o moderna, a partir de una mirada histórica que contempla el paisaje completo del pasado humano y de la vida. Se plantea que el dilema central es entre tradición y modernidad, y que para remontar la crisis se requiere remontar el dominio del racionalismo, la dependencia de la energía fósil, el abandono al que se ha condenado al individuo y la fase corporativa del capitalismo. Se identifica la construcción del poder social como la piedra axial de una ecología política verdaderamente emancipadora. Se concluye que las próximas décadas serán cruciales pues se habrá de vivir el conflicto supremo entre el mono demente y el mono pensante, entre los intereses particulares y perversos y la conciencia cósmica. De ello dependerá la supervivencia de la especie humana o su desaparición.

Palabras clave: Crisis de civilización; poder social; conciencia de especie, conciencia cósmica.

\section{Ten theses on the crisis of modernity}

Abstract: A brief summary is presented on the meaning of the crisis of industrial or modern civilization, from an historical perspective that covers the entire landscape of the human past and of life. It is argued that the central dilemma is between tradition and modernity, and that to overcome the crisis is required overcome the domain of rationalism, the dependence on fossil energy, the abandonment to which the individual has been convicted and the corporate phase of capitalism. The construction of social power is identified as the axial stone of a truly emancipatory political ecology. We conclude that the coming decades will be crucial as we will live the ultimate conflict between the insane ape and the thinking ape, between particular and perverse interests and cosmic consciousness. On that depends the survival of the human species or its disappearance.

Key words: Crisis of civilization; social power; species consciousness, cosmic consciousness.

\section{Dez Teses sobre a crise da modernidade}

Resumo: É um breve resumo do que significa a crise da civilização industrial e moderna, a partir de uma perspectiva histórica, que abrange toda a paisagem do passado humano e da vida. Argumenta-se que o dilema central é entre tradição e modernidade, e para superar a crise requer superar o domínio do racionalismo, a dependência de energia fóssil, o abandono a que o indivíduo foi condenado, a fase do capitalismo corporativo. Identifica-se a construção do poder social como a pedra axial de uma ecologia política verdadeiramente emancipatória. Conclui-se que as 
próximas décadas serão cruciais como eles vão viver o conflito final entre o macaco pensante eo macaco louco, entre os interesses particulares e perversos ea consciência cósmica. Isto contribui para a sobrevivência da espécie humana ou o seu desaparecimento.

Palavras-chave: crise da civilização, poder social, a consciência de espécies, a consciência cósmica.

$$
* * *
$$

1. La Mirada Histórica. Resulta imposible una visión acertada de la crisis actual, si se carece de una perspectiva histórica. Pero no solamente de la historia de los historiadores, sino la historia de los arqueólogos, de los paleontólogos, de los biólogos, de los geólogos y de los astrofísicos. El panorama revelado por la investigación científica, es decir por el pensamiento racional, ofrece datos concretos acerca del devenir humano y social, del mundo vivo, del planeta y del universo. Comprender la vida o el devenir del planeta o la evolución de los homínidos, resulta necesario para entender los procesos sociales. Buena parte de la tozudez humana proviene de la estrechísima mirada de los analistas y estudiosos, de su ausencia de memoria, de su visión casi instantánea, rasgo inequívoco de la propia crisis.

2. Crisis de civilización. El mundo moderno es un invento social de hace apenas unos trescientos años. Un origen difícil de precisar pero que se ubica en algún punto donde confluyen industrialismo, pensamiento científico, mercado dominado por el capital y uso predominante de petróleo. El inicio de la ciencia puede fecharse de manera “oficial”, en 1662 y 1666, años en que se fundaron las primeras sociedades científicas en Inglaterra y Francia. El estreno de un pozo petrolero regurgitando "oro negro" tuvo lugar el 17 de agosto de 1859 en el sureste norteamericano. La industrialización y el capitalismo son procesos difíciles de datar, pero ambos no van más allá de los tres siglos.

En la perspectiva de la historia de la especie, de unos 200,000 años, la aparición de la era moderna ocurrió en apenas «un abrir y cerrar de ojos». En unas cuantas décadas se pasó de un metabolismo orgánico a un metabolismo industrial. La crispación que hoy se vive se debe, fundamentalmente, a lo ocurrido en los últimos cien años, un lapso que equivale solamente al 0.05\% de la historia de la especie humana. En el parpadeo del último siglo, todos los procesos ligados al fenómeno humano se aceleraron, incrementando sus ritmos a niveles nunca vistos y generando fenómenos de tal complejidad que la propia capacidad del conocimiento humano ha quedado desbordada. El siglo XX ha sido entonces la época de la consolidación del mundo moderno, industrial, capitalista, racional, tecnocrático, y de su expansión por todo el planeta.

Vivimos una crisis de la civilización industrial cuyo rasgo primordial es la de ser multidimensional, pues reúne en una sola trinidad a la crisis ecológica, a la crisis social y a la crisis individual, y dentro de cada una de 
estas a toda una gama de (sub)dimensiones. Esto obliga a orquestar diferentes conocimientos y criterios dentro de un solo análisis, y a considerar sus ámbitos visibles e invisibles. Se equivocan quienes piensan que la crisis es solamente económica o tecnológica o ecológica. La crisis de civilización requiere de nuevos paradigmas civilizatorios y no solamente de soluciones parciales o sectoriales. Buena parte de los marcos teóricos y de los modelos existentes en las ciencias sociales y políticas están hoy rebasados, incluidos los más críticos.

Estamos entonces en un fin de época, en la fase terminal de la civilización industrial, en la que las contradicciones individuales, sociales y ecológicas se agudizan y en el que la norma son cada vez más los escenarios sorpresivos y la ausencia de modelos alternativos. Vista así, la crisis requiere de un esfuerzo especial, pues se trata de remontar una época que ha afectado severamente un proceso histórico iniciado hace miles de años, de relaciones visibles e invisibles: el metabolismo entre la especie humana $\mathrm{y}$ el universo natural.

3. El papel crucial de la ciencia y la tecnología. Estos últimos tres siglos han sido una sucesión continua de transformaciones vertiginosas, inusitadas y hasta compulsivas. La ciencia apuntaló a través de la tecnología el desarrollo del capitalismo y éste impulsó a niveles inimaginables el desarrollo de la ciencia. El conocimiento permitió la construcción de máquinas cada vez más sofisticadas, de edificios, puentes, aparatos, carreteras, substancias artificiales, fuentes de energía, materiales diversos, medicamentos, organismos manipulados, medios de comunicación y de transporte. El poder de la especie humana se multiplicó a niveles sin precedentes, tanto para construir como para destruir. El mundo moderno, profano y pragmático, que fue y sigue siendo un producto del conocimiento racional, modificó radicalmente visiones, instituciones, reglas, costumbres, comportamientos y relaciones sociales. El conocimiento, en íntima relación con la empresa, triunfó sobre todas las cosas, y transformó como nunca antes.

La ciencia (y sus tecnologías) al servicio del capital, es por fortuna dominante pero no hegemónica. Contrariamente a lo que se pregona y sostiene, no hay una sola ciencia ("La Ciencia”) sino muchas maneras de concebir y de hacer ciencia y de producir tecnologías. Al interior de la gigantesca comunidad científica existen minorías críticas de contracorriente que buscan un cambio radical del quehacer científico y la democratización del conocimiento. Por ello, toda superación de la crisis actual supone un cambio radical en la manera de generar y aplicar ciencia y tecnología. Mientras no existan propuestas alternativas de conocimiento científico no podrá remontarse la crisis; el conocimiento seguirá encadenado al capital.

4. Tradición y Modernidad. Una de las claves para la correcta comprensión de la crisis de la modernidad, y su posible superación, atañe a la significación cultural de los mundos que se ubican antes o por fuera de ese mundo moderno. Las periferias espaciales y temporales que por fortuna aún existen como enclaves pre-modernos o pre-industriales, son estratégi- 
cas para la remodelación de la sociedad actual. Por lo común lo tradicional se opone (contrasta) a (con) lo moderno.

Durante más del 99\% de su historia, el ser humano aprendió a convivir y a dialogar con la naturaleza, al considerarla una entidad sagrada y al concebir a sus principales elementos como deidades y dioses. También aprendió a formar colectivos basados en la cooperación y la solidaridad, la sabiduría de los más viejos y el uso de una memoria comunitaria y tribal. La época de oro de la especie humana tuvo lugar hace unos 5,000 años cuando cerca de 12,000 culturas, distinguidas por la lengua y distribuidas por todos los hábitats del planeta, aprendieron a vivir en comunidades o aldeas soportadas por relaciones armónicas con sus recursos locales. La aparición de sociedades no-igualitarias cada vez más complejas, permitió el incremento de la población, del comercio y del conocimiento, pero también desencadenó usos imprudentes de los recursos naturales.

La historia que siguió a esa época de equilibrio, no ha sido más que la historia de una doble explotación, social y ecológica, un largo proceso de degradación y decadencia que alcanza su cenit con el advenimiento de la modernidad. Hoy como nunca antes, a pesar de los avances tecnológicos, informáticos y sociales (como la democracia), la especie humana y su entorno planetario sufren los peores procesos de explotación y destrucción.

En lo que queda de tradicional en el planeta, 7,000 pueblos indígenas con una población estimada en 400 a 500 millones, se encuentran las claves para la remodelación de las relaciones sociales y de las relaciones ecológicas, hoy convertidas en meras formas de explotación del trabajo humano y de la naturaleza. Por ello resultan de enorme interés los experimentos políticos que viven países como Bolivia y Ecuador donde los gobiernos se nutren de elementos de la cosmovisión indígena. Ello no significa una vuelta romántica al pasado (tentadora opción), sino la síntesis entre tradición y modernidad, que es la disolución de su conflicto. Pues así como no se pueden eliminar los preceptos rescatables de lo tradicional, tampoco se pueden desdeñar los de los tiempos modernos.

5. La crisis del racionalismo y el re-encantamiento del mundo. La ciencia dio lugar al nuevo «cosmos oficial» del mundo moderno. El conocimiento científico ha revelado el macrocosmos y el microcosmos, desconocidos ambos por los seres pre-modernos. Sobre este cosmos profano que reconoce todo ciudadano moderno, se montan, a manera de componentes no deseados, toda una serie de otros cosmos, secundarios, marginales o alternativos, que se empeñan por mantener vigente, de mil maneras, un cosmos sagrado.

Pero el imperio de la razón, generó a su vez una nueva contradicción. El racionalismo, que ineludiblemente separa al sujeto del objeto de su observación y análisis, profanó una visión del mundo que había prevalecido y operado exitosamente durante el largo pasado, y quebró la unidad que existía entre individuo, sociedad y naturaleza. Esta vez la visión 
secularizada, objetiva y científica de la realidad, prometió mitigar la angustia mediante una oferta tentadora: la construcción de un mundo pleno de satisfactores, cómodo y seguro, donde quedarían satisfechas la mayor parte de las necesidades. Este «mundo feliz» tendría como sus fundamentos el uso creciente y perfeccionado de los conocimientos científicos y tecnológicos, puntualmente orientados por un ente económico superior: el mercado. La fe en el progreso, el desarrollo y un futuro cada vez mejor, compensó la ausencia de creencias divinas en la que devino la nueva concepción moderna y racional de la realidad. Pero esta sustitución que dejó atrás el encantamiento del mundo, condenó al mono racional a vivir frente a una realidad que se analiza y se fracciona por medio de instrumentos, fórmulas, teoremas, ecuaciones, experimentos, pero que de nuevo carece de un significado como totalidad. El ser moderno, ha quedado a la deriva desprovisto de brújula; por ello se hace necesario un re-encantamiento del mundo, una reconexión del individuo consigo mismo, con los otros y con la naturaleza, que no es más que el concepto del "buen vivir” de las cosmovisiones indígenas.

6. El individuo olvidado. En un mundo orientado por una racionalidad instrumental, materialista y tecnocrática, las soluciones a la crisis se buscan por lo común en los procesos de innovación tecnológica, los ajustes al mercado, los productos que se consumen, los sistemas de producción, los instrumentos financieros o políticos, los medios masivos de comunicación; y muy rara vez en el individuo, en el ser y sus expresiones más cercanas, sutiles y profundas: su cultura, su comunicación, sus problemáticas, sus relaciones con él mismo y con los demás, incluidas sus maneras de organizarse y de resistir. No se puede buscar la transformación de las «estructuras externas» y visibles de los procesos vastos y gigantescos de la sociedad y de la naturaleza, sin explorar el mundo (interno, doméstico y organizacional) del individuo. El ser humano, es un ente complejo que busca el equilibrio entre razón y pasión, pensamiento y sentimiento, cuerpo y espíritu. Es un ser cuyas conductas y decisiones se rigen no solamente por el mundo conciente del día sino por el universo inconciente de la noche y de los sueños. El ser humano, la cultura a la que pertenece y que recrea, sus vidas cotidianas, y las instituciones y organizaciones que inventa para enfrentar, resistir y remontar la crisis, son las claves ocultas, las dimensiones intangibles que la reflexión crítica debe integrar. Es Occidente por fin mirando a Oriente.

7. La conciencia de especie. Hoy, el conocimiento coherente y completo de los procesos históricos y actuales, naturales y sociales, permite al ser humano adquirir una conciencia sin concesiones. Una mirada limpia sobre lo que acontece. La conciencia de especie permite recobrar una percepción original del ser humano, hoy casi olvidada o suprimida en la realidad industrial: la de su pertenencia al mundo de la naturaleza. También lo conduce a restablecer un comportamiento solidario con sus semejantes vivientes (humanos y no humanos) y no vivos y a edificar una ética de la supervivencia basada en la cooperación, la comunicación y la comprensión de una realidad compleja. 
Bajo la conciencia de especie ya no sólo se pertenece a una familia, a un linaje, a una comunidad, a una cultura, a una nación, o a una cofradía religiosa o política. Antes que todo se es parte de una especie biológica, dotada de una historia y necesitada de un futuro, y con una existencia ligada al resto de los seres vivos que integran el hábitat planetario y, por supuesto, en íntima conexión con el planeta mismo. La conciencia de especie otorga a los seres humanos una nueva percepción del espacio (topoconciencia) y del tiempo (cronoconciencia), que trasciende la estrechísima visión a la que le condena el individualismo, racionalismo y pragmatismo del homo economicus.

8. La era del poder social. Hoy vivimos el pináculo del capital y, más específicamente, del capitalismo corporativo. Como nunca antes las grandes compañías han tenido ganancias record, y si no, si han entrado en bancarrota, se han dado el lujo de ser rescatadas por los impuestos ciudadanos. Esto ha sido así porque el poder económico ha sojuzgado al poder político, hasta tal punto que en muchos casos es imposible distinguir si se trata de un político que se dedica a los negocios o un empresario que se dedica a la política (ahí están los casos emblemáticos de G. Bush, V. Fox, S. Berlusconi y S. Piñera). Frente a esta amalgama de intereses, la gran derrotada ha sido la sociedad civil, los ciudadanos que han visto menguado su poder de decisión. Hoy, la devastación del mundo de la naturaleza corre en paralelo a la explotación del esfuerzo de los trabajadores. Solo, el capital liberado de candados y restricciones, destruiría al planeta entero si ello fuera rentable, de la misma manera que exprimiría hasta la última gota de sudor de los empleados y trabajadores, y abusaría impíamente de los consumidores.

El gran desafío es entonces la re-constitución del poder social y el control ciudadano sobre los procesos económicos y políticos. Ello supone construir o re-construir el poder social en territorios concretos. En esta perspectiva, la superación de la crisis será la sustitución paulatina y gradual de las actuales instituciones por aquellas creadas por el poder ciudadano. A las gigantescas compañías monopólicas seguirán las cooperativas, microempresas y empresas de escala familiar; a los grandes bancos, cajas de ahorro, bancos populares y cooperativas de crédito; a las cadenas comerciales el comercio justo, orgánico y directo entre productores y consumidores. A la producción estatal o privada de energías fósiles y del agua, seguirá la producción doméstica o comunitaria de energías solares y renovables y de agua; a los grandes latifundios, base de los agro-negocios, las reformas agrarias de inspiración agro-ecológica; a los espacios naturales, escénicos y de esparcimiento hoy privatizados, su reconversión en espacios públicos y gratuitos administrados por los ciudadanos locales. Y, naturalmente, los presupuestos participativos.

9. ¿Revolución o metamorfosis? Aunque muchas cosas han cambiado, un precepto que sigue vivo no obstante su obsolescencia es la idea de revolución, de cambio súbito y violento. Imbuido de una fuerza épica descomunal, la idea de revolución encierra dones sagrados como el sacrifi- 
cio, la entrega, la gloria, el heroísmo, todo lo cual da un sentido a la existencia de quienes se involucran. Hoy, en la era de la comunicación, la información, el conocimiento y la democracia, el cambio social requiere de nuevas fórmulas. La sociedad civil organizada, liberada ya del control de los poderes económico y político, debe conformar núcleos, redes, organizaciones basadas en la cooperación, el conocimiento, la comunicación y la toma democrática de decisiones. La construcción del poder social en territorios concretos, debe ser un proceso expansivo, combinado cuando sea posible con la toma del poder político, en este caso con el único fin de consolidar, multiplicar y expandir... el poder social. Ello da lugar a una nueva idea de cambio, como proceso gradual y acumulativo, y por ello recuerda al fenómeno de la metamorfosis. Dejar atrás la idea de revolución para sustituirla por la de metamorfosis, otorga una visión anclada en la vida cotidiana, que se expresa en acciones concretas, y que permite proyectar el cambio en el corto, mediano y largo plazo.

10. ¿Homo sapiens u Homo demens? Quienes hoy alcanzan a vislumbrar limpiamente la situación que se vive, que lo mismo produce angustia que temor, parálisis o desilusión, logran rescatar la dimensión más acabada del pensamiento crítico. Que no es de izquierda ni de derecha, ni conservador ni progresista, pues hoy las geometrías ideológicas han quedado rebasadas. Ellos han adquirido una "conciencia de especie", una "ética planetaria", una "inteligencia global". Esta conciencia es fundamentalmente el reconocimiento de que la nuestra es también una especie mortal, una especie que dependiendo de las acciones actuales presentes y futuras puede llegar a desaparecer, y que por lo mismo se ha vuelto una especie amenazada de extinción. Lo anterior obliga a plantear las siguientes preguntas: ¿No hay en realidad una brecha tajante y profunda entre el ser humano dotado de esa conciencia de especie y el que carece de ella? ¿ ¿No parece que se procrean en realidad dos especies (sociales, culturales, ontológicas) dentro de un mismo gremio biológico? ¿No estamos por lo tanto frente a dos miembros radicalmente distintos de una misma especie biológica? En suma, ¿no estamos reconociendo a dos especies diferentes, el "mono demente" (Homo demens) y el "mono pensante" (Homo sapiens), de cuya conflictividad y su resolución dependerá el futuro de la humanidad, el resto de los seres vivos y el planeta entero? 
Polis, Revista de la Universidad Bolivariana, Volumen 11, $N^{\circ}$ 33, 2012

\section{Notas}

${ }^{1}$ Publicado en: Rojo Amate 2: 7-11. 2010. www.rojoamate.com

${ }^{2}$ Las 10 tesis aquí enunciadas, se encuentran más desarrolladas en mis ensayos: “¿Contra Nosotros? La conciencia de especie y el surgimiento de una nueva filosofía política” (2009). En Polis. Revista de la Universidad Bolivariana, Vol. 8 N 22: 219-228 (www.scielo.cl/pdf/ polis/v8n22/art13.pdf.); y "Las claves ocultas de la sostenibilidad: transformación cultural, conciencia de especie y poder social”. En La Situación del Mundo 2010. Icaria Editorial y World Watch Institute. Madrid. 